\title{
Planejamento de turnos de trabalho: uma abordagem no setor sucroalcooleiro com uso de simulação discreta
}

\author{
Work shift planning: an approach to the \\ sugarcane sector using discrete simulation
}

\author{
João Eduardo Azevedo Ramos da Silva ${ }^{1}$ \\ Maria Rita Pontes Assumpção Alves ${ }^{2}$ \\ Miguel Antonio Bueno da Costa ${ }^{3}$
}

\begin{abstract}
Resumo: O Brasil é o maior produtor de cana-de-açúcar do mundo, sendo responsável pela geração de 3 milhões de empregos em toda a sua cadeia de suprimentos. A alimentação constante das moendas durante o período de safra depende do bom gerenciamento das operações de corte, carregamento e transporte de cana-de-açúcar das fazendas para as usinas. A entrega de cana-de-açúcar deve ser garantida para que o risco de parada da produção industrial de açúcar e álcool seja evitado. Este trabalho foca o desenvolvimento e a utilização de um modelo de simulação discreta para a determinhação do sistema de turnos de trabalho dos operadores de equipamentos agrícolas de uma usina no Estado de São Paulo, considerando os requisitos de moagem, o risco da falta de matéria-prima e o limite permitido das jornadas de trabalho. Quatro cenários foram propostos para avaliação, sendo o primeiro com a troca de turnos unificada às 7 e às 19 horas; e os demais com a entrada em operação de uma das frentes de corte e carregamento com 2, 4 e 6 horas de defasagem em relação às demais frentes (escalonamento). O cenário com escalonamento de quatro horas de defasagem apresentou o melhor desempenho ao conciliar a entrega de cana, as jornadas de trabalho e o risco de desabastecimento. A discussão é focada no caso selecionado, mas estudos similares podem ser aplicados a outras usinas de açúcar e álcool ou a outros processos do setor sucroalcooleiro.
\end{abstract}

Palavras-chave: Simulação de sistemas. Corte, carregamento e transporte. Setor sucroalcooleiro.

\begin{abstract}
Brazil is the world's greatest producer of sugarcane generating 3 million jobs within its supply chain. The continuous feeding of sugarcane mills during the harvest season strongly depends on the good management of harvest and operations of loading and transporting the sugarcane from farms to mills. A guaranteed delivery of sugarcane must be developed to avoid the risk of stopping the production of sugar and alcohol. This study focuses on the development and use of a computer simulation model to evaluate and select a suitable work shift system for agricultural equipment operators of a cane sugar mill in the State of São Paulo, Brazil based on three criteria: sugarcane delivery requirements, lack of sugarcane, and legal restrictions on daily working hours. Four scenarios were selected for evaluation. The scenario that presents a 4-hour shift system was considered the best option since it fulfilled most of the requirements under analysis. The discussion is focused on work shift planning, but similar studies can be applied in other sugar and alcohol mills and other sugar and alcohol processes of the sugarcane sector.
\end{abstract}

Keywords: Simulation. Cutting, loading and transportation. Sugarcane.

\section{Introdução}

Segundo dados do Ministério da Agricultura, Pecuária e Abastecimento (BRASIL, 2009), o Brasil é o maior produtor de cana-de-açúcar do mundo, com área plantada de 8,4 milhões de hectares e uma safra anual de 558 milhões de toneladas de cana.
As operações de corte, carregamento e transporte (CCT) de cana-de-açúcar envolvem equipamentos de custo elevado, tais como colhedoras, carregadoras, tratores e caminhões. O planejamento da utilização desses recursos requer decisões que não se limitam

\footnotetext{
${ }^{1}$ Laboratório de Ergonomia, Simulação e Projeto de Situações Produtivas: Ergo\&Ação - SIMUCAD, Universidade Federal de São Carlos - UFSCar, campus Sorocaba, Rod. João Leme dos Santos, Km 110 - SP-264, CEP 18052-780, Sorocaba - SP, Brasil, E-mail: jesilva@ufscar.br

2 Departamento de Engenharia de Produção, Universidade Federal de São Carlos - UFSCar, campus São Carlos, Rod. Washington Luís, Km 235, SP-310, CEP 13565-905, São Carlos - SP, Brasil, E-mail: rita@dep.ufscar.br

${ }^{3}$ Laboratório de Ergonomia, Simulação e Projeto de Situações Produtivas: Ergo\&Ação - SIMUCAD, Departamento de Engenharia de Produção, Universidade Federal de São Carlos - UFSCar, campus São Carlos, Rod. Washington Luís, Km 235, SP-310,

CEP 13565-905, São Carlos - SP, Brasil, E-mail: mbcosta@ power.ufscar.br
}

Recebido em 6/1/2010 — Aceito em 29/11/2010

Suporte financeiro: Nenhum. 
apenas à sua quantificação. Outros aspectos também devem ser gerenciados como a forma de operá-los, a localização das frentes de corte e o estabelecimento dos turnos de trabalho e horários de refeição dos operadores. O planejamento das operações deve ocorrer de modo coordenado e numa visão sistêmica, uma vez que uma decisão sobre um quesito acarreta interferência direta em todo o sistema, dada a forte interação entre os recursos envolvidos.

Esse esforço de planejamento é decisivo para a manutenção da entrega de cana-de-açúcar para moagem. A fabricação de açúcar e álcool é contínua, 24 horas por dia, de maio a novembro na região Centro-Sul. Como a cana se deteriora à medida que aumenta o tempo entre sua colheita e a moagem, a sua entrega deve ser rápida para evitar a perda de qualidade, o que compromete a eficiência industrial. Os gestores das usinas têm a responsabilidade de coordenar as operações de CCT para proporcionar matéria-prima de qualidade e sem falha de abastecimento, uma vez que os custos de setup na indústria são muito altos. A busca por matéria-prima de melhor qualidade tem levado as usinas a reduzir a quantidade de cana estocada no pátio. Para isso, a confiabilidade do sistema de transporte deve ser alta.

Para auxiliar a tomada de decisão no planejamento das operações de CCT, uma das alternativas é utilizar a simulação computacional. As vantagens da simulação derivam do conhecimento prévio do desempenho dos sistemas e da possibilidade de manipular cenários para testar situações de interesse. Um ponto forte é o respeito à aleatoriedade do tempo de duração dos processos, dado pelo uso de distribuições de probabilidade. Adicionalmente, a análise de alguns sistemas mais complexos é possível apenas mediante o uso de simulação, pela possibilidade de abordar adequadamente a interação entre recursos e entidades.

Se as relações que compõem um modelo são simples o suficiente, pode ser possível utilizar métodos matemáticos (como álgebra, cálculo ou teoria de probabilidades) para obter informações exatas sobre questões de interesse; o que é conhecido como solução analítica. Porém, a maioria dos sistemas do mundo real é muito complexa para ser avaliada analiticamente e estes modelos devem ser estudados por meio de simulação [...] (LAW; KELTON, 1991, p. 1).

E ainda:

Se uma solução analítica para um modelo matemático é disponível e é computacionalmente eficiente, é usualmente desejável estudar o modelo dessa forma ao invés de se utilizar simulação. Porém muitos sistemas são altamente complexos, tornando-se impossível qualquer solução analítica. Nesse caso, o modelo deve ser estudado por meio de simulação, ou seja, numericamente, executando-se o modelo com as entradas em questão para verificar como estas afetam as medidas de desempenho de saída [...] (LAW; KELTON, 1991, p. 6).

Uma vez que o sistema de CCT das usinas é formado por operações realizadas simultaneamente por equipamentos diferentes, em frentes de corte e carregamento distintos, o uso de outras abordagens não permite a análise da interação entre os equipamentos da mesma maneira que a simulação faz. A simulação pode levantar informações como estatísticas de filas (tempos e quantidade de entidades nas filas), ociosidade de equipamentos e o comportamento de variáveis durante o período simulado.

Assim, uma vez que o modelo é validado, é possível submetê-lo a diversas condições operacionais e avaliar o resultado de diferentes cenários. A avaliação prévia de cenários, sem implementá-los, permite reduzir erros, compreender como os recursos interagem e explorar previamente as particularidades dos sistemas para auxiliar a decisão.

\section{Referencial teórico}

\subsection{Simulação computacional}

$\mathrm{Na}$ definição de Kelton, Sadowski e Sadowky (1998), simulação é o processo de projetar e criar um modelo em computador de um sistema real ou proposto, com o propósito de conduzir experimentos numéricos para fornecer uma melhor compreensão do comportamento do sistema, dada uma série de condições. A simulação envolve a geração de uma história artificial do sistema e a sua observação, para direcionar inferências envolvendo as características do sistema real que estão sendo representadas (BANKS, 1998). Dois tipos de simulação podem ser utilizados em função da forma de mudança das variáveis de estado do sistema. A simulação discreta representa sistemas cujas variáveis se modificam em instantes pontuais do tempo, enquanto na simulação de sistemas contínuos, as variáveis podem mudar continuamente em relação ao tempo (KELTON; SADOWSKI; SADOWSKI, 1998).

Freitas Filho (2008) lista vantagens e desvantagens da simulação, baseadas nos textos de Pegden, Shannon and Sadowski (1991) e Banks (1984). Algumas das vantagens listadas são: a possibilidade de se utilizar o modelo inúmeras vezes para avaliar projetos e políticas propostas; a possibilidade de se avaliar sistemas ainda não existentes, mesmo que os dados de entrada sejam rudimentares; e a possibilidade de identificação de gargalos, que é a preocupação maior no gerenciamento operacional de inúmeros sistemas. Por outro lado, as desvantagens referem-se à necessidade de conhecimento específico do software utilizado, ao tempo requerido para a elaboração dos modelos e à difícil interpretação dos resultados fornecidos pelos modelos quando, por vezes, não se sabe se um 
determinado resultado foi atingido devido à alteração do valor de uma variável ou se ele deriva da interação de recursos e entidades durante a simulação. Uma vez que a simulação utiliza distribuições teóricas de probabilidade, a combinação de tais curvas pode gerar um resultado de difícil interpretação.

Diversos autores sugerem roteiros a serem seguidos num projeto de simulação. Banks (1998), Law, Kelton (1991), Freitas Filho (2008) e Pegden, Shannon and Sadowski (1995) apresentam propostas que apesar da quantidade diferenciada de passos, possuem procedimentos semelhantes na maneira de conduzir os projetos. Todos os autores recomendam atenção especial na definição do objetivo do trabalho, que norteia todo o desenvolvimento das etapas subsequentes. Dependendo do objetivo estipulado, há variação nos dados a coletar e na tradução do sistema real para o modelo de simulação.

Da mesma maneira, a fase de validação está presente no roteiro de todos os autores, para garantir a correspondência entre os sistemas real e simulado, o que requer que a coleta de dados seja bem feita. Tomando-se como referência o roteiro apresentado por Pegden, Shannon and Sadowski (1995), o projeto de simulação possui doze passos, que podem ser agrupados em três fases sequenciais: conceituação e infraestrutura, modelagem e simulação (Figura 1).

A primeira fase, conceituação e infraestrutura, busca a compreensão do sistema de interesse e o estabelecimento da estrutura necessária para a boa condução do projeto. A fase de modelagem constitui o detalhamento do sistema e a sua representação por um modelo computacional. A última fase, simulação, corresponde ao estudo do sistema conforme projeto experimental delineado, a análise dos resultados por meio das corridas de simulação e sua implementação.

\subsection{Aplicações de simulação computacional no setor sucroalcooleiro}

Trabalhos que envolvem modelagem e simulação de sistemas de corte, carregamento e transporte de cana-de-açúcar são muito comuns em países onde a atividade sucroalcooleira exerce grande importância, tais como Brasil, Austrália, África do Sul, Cuba e Índia.

Hansen, Barnes e Lyne (2001) elaboraram modelo de simulação para uma usina da África do Sul para estimar o impacto e a efetividade de efetuar mudanças no sistema de colheita e transporte de cana-de-açúcar, para reduzir o tempo entre a colheita e a moagem.

Díaz e Perez (2000) realizaram um trabalho de simulação e otimização da operação de transporte de cana-de-açúcar. Foram obtidas superfícies (conjuntos de soluções viáveis, considerando mais que duas dimensões) de resposta de cana transportada e de tempos de ciclo de caminhões em função do número de caminhões e reboques utilizados.

Utilizando o conceito de simulação e modelagem por redes de Petri, Yamada, Porto e Inamasu (2002) representaram a cadeia produtiva sucroalcooleira em 14 etapas, desde o plantio da cana até o armazenamento dos produtos e a geração de vapor através do bagaço.

Ianonni (2000) utilizou simulação para abordar a recepção de cana-de-açúcar em uma usina. Foi avaliado o tempo de permanência na área industrial de diversas configurações de transporte, as regras de despacho dos caminhões para os pontos de descarga e a quantidade de cana moída.

Focando a simulação de sistemas de corte, carregamento e transporte de cana-de-açúcar de maneira integrada, Milan (1992) descreveu o sistema de produção sendo formado por quatro subsistemas

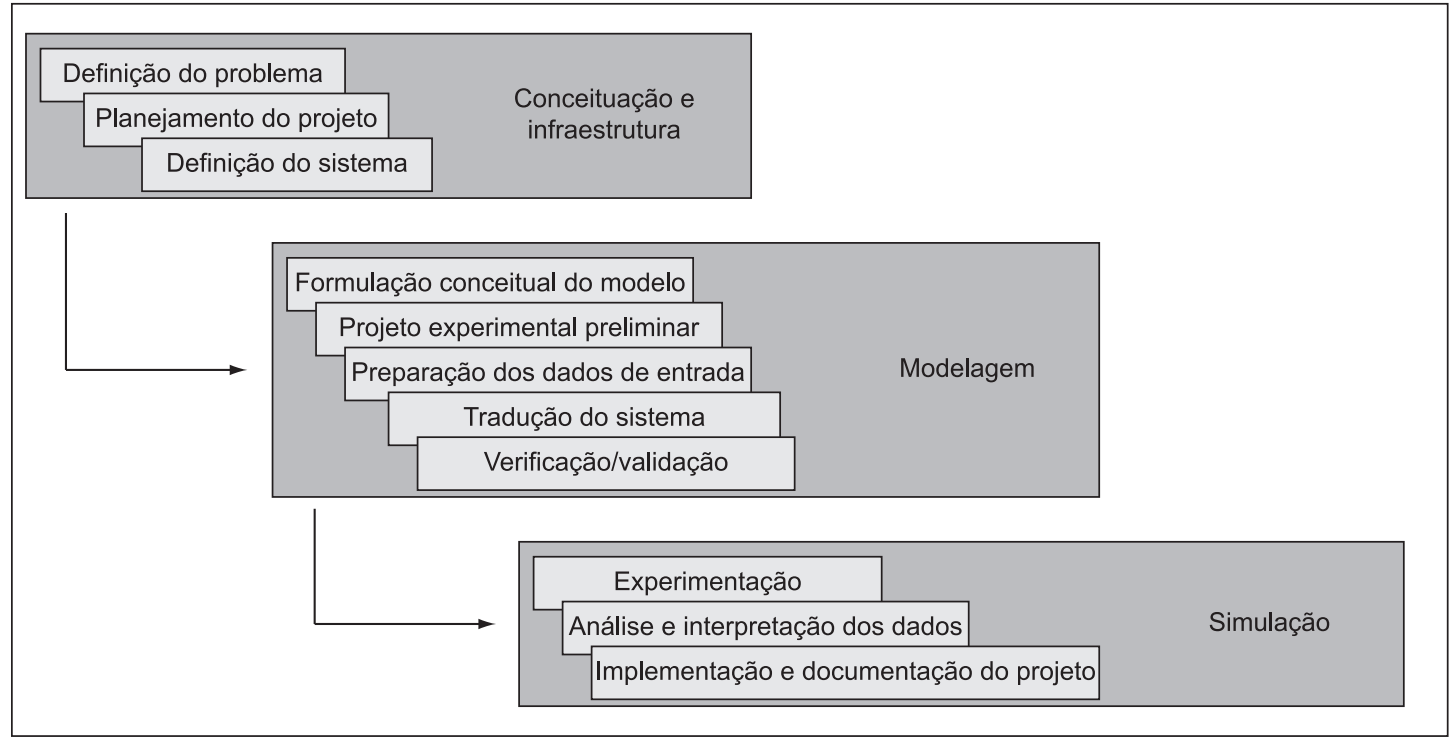

Figura 1. Passos de um projeto de simulação. Elaborado a partir de Pegden, Shannon e Sadowski (1995). 
que se relacionam: Agronomia, Colheita, Transporte e Mecanização.

Lopes (1995) elaborou simulação de custo do sistema de carregamento e transporte de cana-de-açúcar utilizando planilhas eletrônicas MS Excel. O trabalho determinou o custo de carregamento e transporte de cana a partir de equações empíricas da capacidade operacional de carregamento e da velocidade média de veículos. Os parâmetros comprovados de maior influência foram o aumento da carga transportada pelos caminhões e o aumento da eficiência operacional dos equipamentos.

Rípoli e Rípoli (2004) atestaram que o dimensionamento da frota canavieira, especificando quantidade e tipo de veículos mais convenientes exige conhecimento e responsabilidade do tomador de decisões. Como auxílio, podem ser usadas metodologias determinísticas ou as que utilizam simulação. Os autores argumentaram que no Brasil, diversas empresas vêm desenvolvendo softwares para auxiliar os centros de processamento de dados das usinas na elaboração de programas dedicados à logística de sistemas de transporte.

\section{Decisões gerenciais típicas de sistemas de corte, carregamento e transporte}

$\mathrm{O}$ gerenciamento de sistemas de corte, carregamento e transporte (CCT) de cana-de-açúcar requer tomadas de decisões frequentes, exigidas pela manutenção do abastecimento contínuo de cana para as moendas. Foi feita uma seleção das principais decisões que fazem parte da gestão das operações de CCT, apresentadas na sequência.

\subsection{Frentes de corte}

A cana-de-açúcar que chega à usina vem de pontos distintos, trabalhada por equipes autônomas, denominadas frentes de cortes que operam com equipamentos diferentes conforme o tipo de corte (manual/mecanizado). A quantidade de frentes de corte é estabelecida pela equipe gerencial das usinas e depende da moagem da usina, da entrega de cana de fornecedores, da quantidade de máquinas alocadas na frente, da distribuição geográfica do canavial e da dimensão das fazendas, o que irá requerer ou não a mudança frequente de área de colheita.

\subsection{Tipos de corte e equipamentos de colheita}

A diferença entre os tipos de corte está no sistema de colheita, que resulta em cana inteira ou cana picada. A complexidade operacional nas frentes se dá pela interação no uso dos equipamentos. O dimensionamento adequado busca maximizar o uso da capacidade dos veículos e máquinas.

$\mathrm{O}$ balanceamento entre os recursos mecanizados (caminhões, colhedoras, tratores reboque, carregadoras e tratores-transbordo) também está sujeito ao conceito de gargalo (bottlenecks), no qual algum dos recursos pode limitar a capacidade operacional de todo o sistema.

\subsection{Equipamentos de transporte}

As composições de transporte de cana mais comuns são apresentadas na Figura 2. O tipo e as dimensões das carrocerias para acomodação da carga variam em função do tipo de cana (inteira ou picada) a ser carregada e da forma de carregamento. Outras variantes importantes relativas ao transporte são a carga transportada por viagem, as velocidades de percurso (vazio e carregado), o tipo de carregamento no campo e o tipo de descarga na usina. Caso o dimensionamento do transporte não esteja adequado, poderão ocorrer falhas de abastecimento de cana na usina.

\subsection{Jornadas de trabalho e trocas de turno}

O procedimento usual de turnos considera o trabalho dos operadores em três turnos de 8 horas, mas algumas usinas trabalham com sistema de dois turnos. Se por um lado o sistema de três turnos

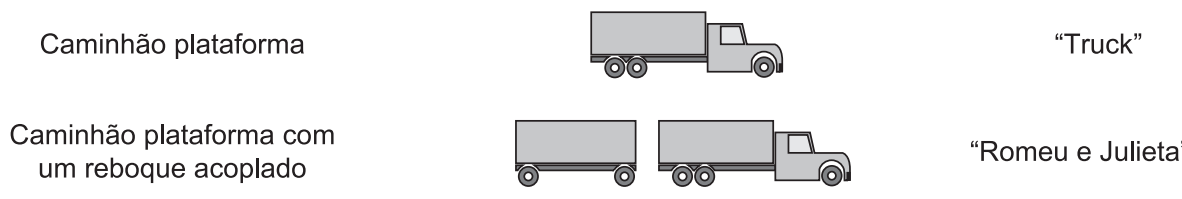

Caminhão plataforma com dois reboques acoplados
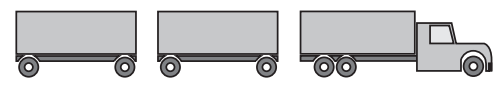

"Treminhão"
Cavalo mecânico com dois semi-reboques acoplados

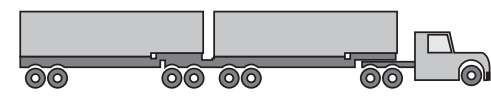

Figura 2. Composições usuais para o transporte de cana. 
aproveita o equipamento durante as 24 horas do dia, esse sistema traz o custo de dispor de operadores adicionais para mais um turno e a necessidade de gerenciar uma troca de turnos adicional por dia em comparação ao sistema de dois turnos.

No sistema de dois turnos, a jornada máxima permitida é de aproximadamente 10 horas (consideraram-se 8 horas trabalhadas e duas horas extras). Como a usina opera 24 horas por dia, caso o sistema de trabalho seja de dois turnos, há a necessidade de se contar com a alimentação da cana armazenada em estoque nos períodos em que houver interrupção do transporte.

\subsection{Estoque de cana}

O estoque de cana garante a alimentação das moendas nos momentos de descontinuidade da entrega. A cana pode ser armazenada de duas maneiras: no pátio ou "sobre rodas". O pátio é um depósito onde a cana inteira é armazenada e cuja movimentação até o ponto de recepção para moagem é feita por meio de pontes rolantes ou pás carregadoras. A cana "sobre rodas" é a prática de manter na usina caminhões e carretas carregados que são movimentados por tratores ou caminhões até os pontos de descarregamento na esteira para moagem.

É importante ressaltar que a manutenção de grandes estoques prejudica a qualidade da cana processada pela elevação das horas de queima. Algumas usinas monitoram constantemente esse estoque, usando-o para determinar o fim da jornada de trabalho dos motoristas e operadores de máquinas, caso o estoque seja suficiente para abastecer a usina até o início do próximo turno.

\section{Operações de corte, carregamento e transporte de cana-de-açúcar}

\subsection{Operações nas frentes de cana inteira}

O esquema apresentado na Figura 3 ilustra as operações típicas de uma frente de cana inteira, com transporte nas configurações "truck", "romeu e julieta" e "treminhão". O uso de "rodotrens" em cana inteira existe, embora seja uma prática menos difundida, pelo risco de promover a compactação do solo com a entrada dos semirreboques na área de colheita.

Os caminhões chegam à frente de cana inteira e se dirigem ao ponto de engate onde fazem o desacoplamento dos reboques e o engate nos tratoresreboque. Na sequência, os caminhões desengatados e os tratores-reboque com as carretas acopladas se deslocam até uma carregadora disponível para efetuar o carregamento.

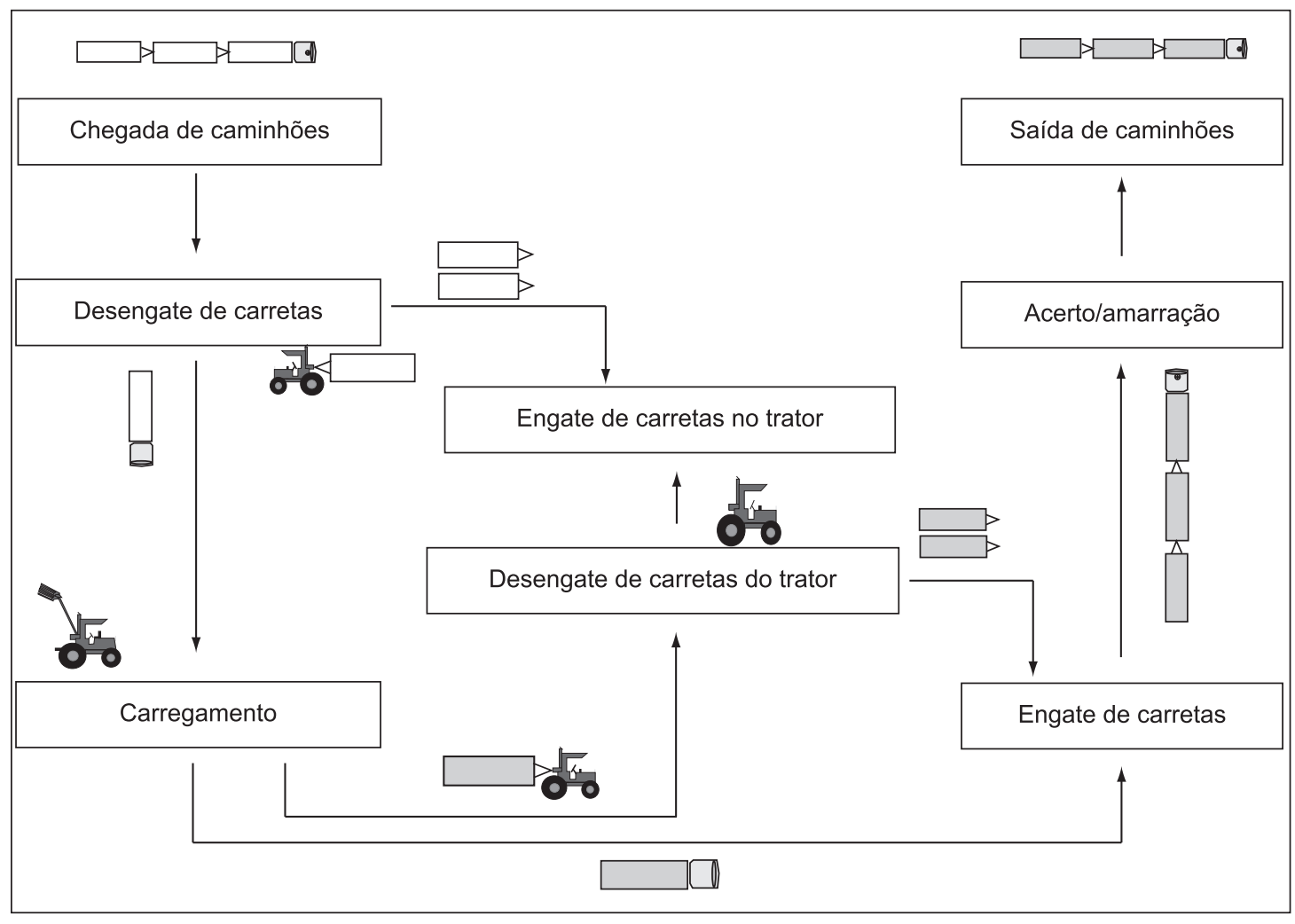

Figura 3. Sequenciamento de operações em frente de cana inteira. 
Após a conclusão do carregamento, os caminhões e os tratores-reboque vão até o ponto de desengate, onde os reboques são desatrelados dos tratores. Após o desacoplamento, os tratores retornam até o ponto de engate para atrelar algum reboque vazio ou simplesmente aguardar a chegada de caminhões.

No ponto de desengate, os reboques carregados são atrelados aos caminhões para formar novamente a composição de transporte completa. Após a montagem do caminhão, são feitas duas operações adicionais: o acerto de carga, quando os colmos de cana são aparados rente à carroceria, e a amarração da carga, quando a carga é presa à carroceria por meio de cabos de aço ou cordas para evitar a perda de colmos no transporte. Finalizadas estas operações, o caminhão retorna à usina.

\subsection{Operações nas frentes de cana picada}

Nesse sistema, os caminhões de cana picada chegam à frente e permanecem estacionados numa área denominada malhador. Os tratores rebocando os transbordos (normalmente 2 unidades) vêm até os caminhões, acionam os pistões hidráulicos e a carroceria dos transbordos se eleva, transferido a carga para os caminhões. Após a transferência, os tratores se dirigem para as colhedoras, que permanecem no interior da área de colheita, para efetuarem um novo carregamento. A colhedora realiza sequencialmente o corte, a picação e a limpeza da cana conduzindo-a para os transbordos. Após a conclusão da carga, os tratores se dirigem novamente para o malhador e transferem a cana para os caminhões, fechando assim o ciclo operacional. Quando a carga dos caminhões está finalizada, estes se dirigem para a usina. A Figura 4 ilustra a movimentação dos equipamentos em uma frente de cana picada.

\subsection{Operações na área industrial}

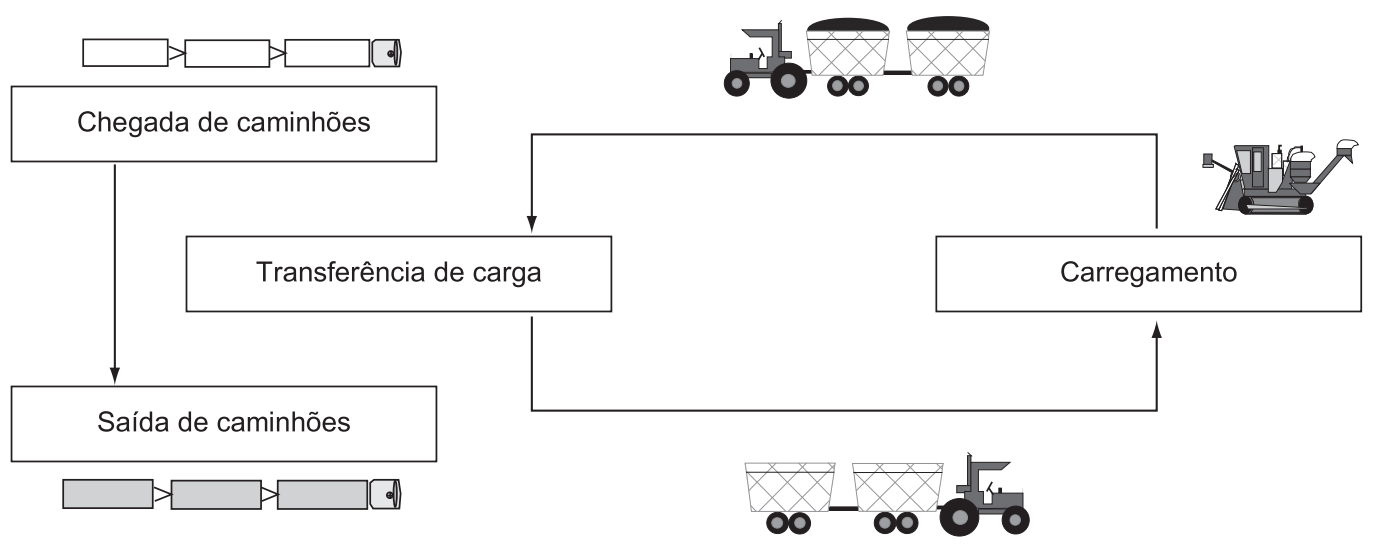

Na usina, o ciclo dos caminhões é bem definido. A primeira operação é a pesagem (peso bruto) para registrar a cana entregue por frente de corte. Na sequência, parte dos caminhões segue para a sonda, onde amostras da carga são retiradas para análise tecnológica (pol, brix, impurezas mineral e vegetal, dentre outras) e o restante segue para a descarga. Após serem descarregados, os veículos de cana inteira passam por um processo de limpeza de carroceria (retirada de colmos de cana) e, em seguida, seguem para a balança para pesagem do peso tara. Os caminhões de cana picada seguem direto para a balança após seu descarregamento. Na balança, o caminhão é pesado novamente e é despachado ao campo para mais uma viagem. A Figura 5 ilustra o sequenciamento das operações na área industrial.

Na usina, nas frentes de cana inteira e nas frentes de cana picada, é possível dispor de reboques ou semirreboques reservas para maximizar a utilização dos caminhões, sobretudo nas frentes de transporte com "rodotrens", devido à flexibilidade do cavalo mecânico.

\section{Estudo de caso}

\subsection{O problema de pesquisa}

O problema de pesquisa deste trabalho pertence ao contexto da gestão de operações e envolve duas das atividades primárias da área de logística: o transporte e a gerência de estoques (BALLOU, 2006; BOWERSOX; CLOSS; COOPER, 2006). Estas atividades-chave são afetadas diretamente pelo regime de turnos de trabalho a ser adotado para as equipes responsáveis pelo abastecimento de matéria-prima em uma indústria (inbound logistic).

A abordagem do trabalho foi quantitativa e o método de pesquisa adotado foi o estudo de caso. $\mathrm{Na}$ definição de Yin (1994), este método busca estudar fenômenos no seu contexto na vida real, especialmente

Figura 4. Sequenciamento de operações em frente de cana picada. 
quando as fronteiras entre o fenômeno e o seu contexto não são evidentes. Procurou-se explorar essas fronteiras de forma a responder perguntas do tipo "Como?" e "Por quê?" De modo particular, este estudo de caso se aplicou a uma situação de fornecimento de um único produto a partir de fontes múltiplas, sujeitas à diversidade de equipamentos,

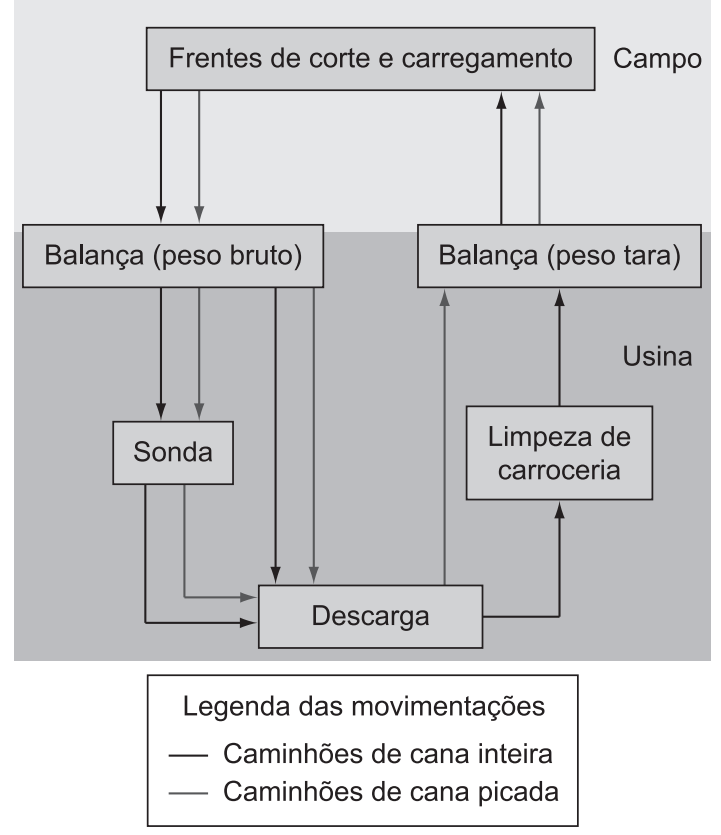

Figura 5. Sequenciamento de operações na indústria. restrições trabalhistas, e outros critérios do ponto de vista de gestão. Buscou-se compreender como regimes diferentes de turnos de trabalho poderiam alterar as horas totais trabalhadas pelos operadores (jornadas) e a variação do estoque de matéria-prima.

Visando comparar quatro sistemas de turnos de trabalho para operadores de equipamentos agrícolas, foi desenvolvido um modelo de simulação do sistema de corte, carregamento e transporte de cana-de-açúcar de uma usina da região de Ribeirão Preto/SP. O sistema foi modelado com cinco frentes de corte e carregamento; duas mecanizadas e três semimecanizadas (corte manual e carregamento mecânico). A capacidade de moagem de cana era de 12.000 t.dia ${ }^{-1}$, sendo $4.000 \mathrm{t}$ de cana picada e 8.000 t de cana inteira. A Figura 6 apresenta uma animação do sistema.

A configuração de transporte vigente era com treminhões, com trocas de turno dos motoristas sempre na usina. A Tabela 1 apresenta resumidamente as principais informações das frentes.

A usina sempre trabalhou com sistema de dois turnos e uma turma, ou seja, todos os operadores de máquinas realizando as trocas de turno simultaneamente em dois horários no dia, às 7 horas (turno do dia - turno 1) e às 19 horas (turno da noite - turno 2). No entanto, nesse sistema, a jornada máxima de trabalho permitida aos operadores, segundo a equipe da usina, era de 10 horas diárias ( 8 horas regulares trabalhadas e 2 horas extras), o que determinava o horário ideal de fim do turno para cada período: 17 horas para o turno

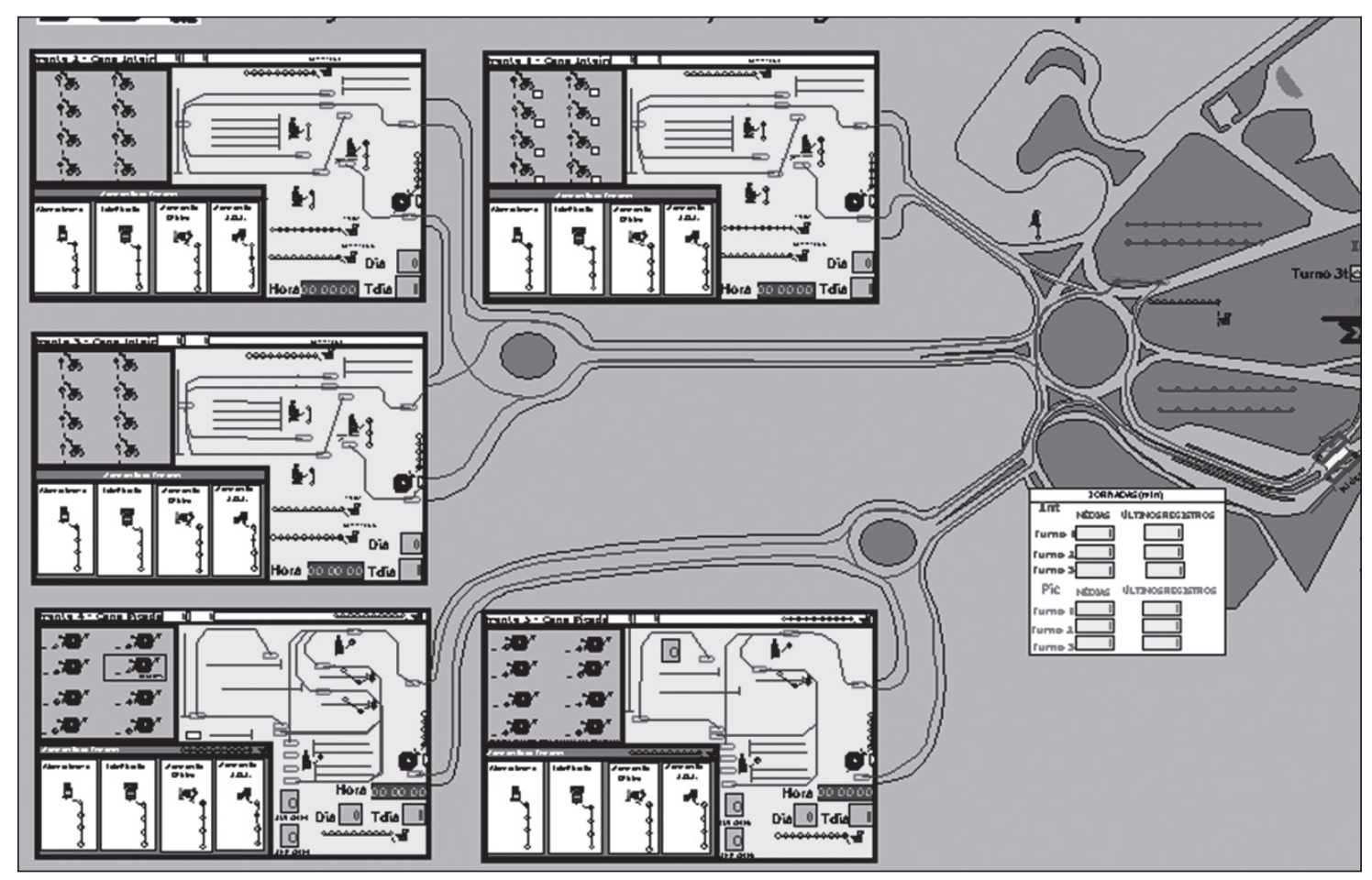

Figura 6. Animação final do modelo de simulação desenvolvido. 
Tabela 1. Caracterização das frentes de corte e carregamento.

\begin{tabular}{lccccccc}
\hline \multicolumn{1}{c}{ Parâmetros } & \multicolumn{7}{c}{ Frente } \\
\cline { 2 - 7 } & $\mathbf{1}$ & $\mathbf{2}$ & $\mathbf{3}$ & $\mathbf{4}$ & $\mathbf{5}$ & Total \\
\hline Tipo de cana & Inteira & Inteira & Inteira & Picada & Picada & - \\
Dist. média ponderada $(\mathrm{km})$ & 13 & 29 & 18 & 25 & 25 & - \\
Qtde. de colhedoras & - & - & - & $6(1$ reserva $)$ & 1 & 7 \\
Qtde. de carregadoras & 6 & 6 & 5 & - & - & 17 \\
Qtde. de tratores-reboque & 5 & 6 & 4 & - & - & 15 \\
Qtde. de caminhões-transbordo & - & - & - & $11(1$ reserva) & 2 & 13 \\
Qtde. de "treminhões" & 6 & 12 & 6 & 9 & 2 & 35 \\
\hline
\end{tabular}

do dia e 5 horas para o turno da noite. No entanto, como o final do turno era vinculado ao cumprimento da cota para abastecimento da usina, havia dias em que o limite de 10 horas trabalhadas por turno era extrapolado.

O sistema de dois turnos possuía a vantagem de se operar com menos trabalhadores por equipamento, tornando maior a responsabilidade e o controle na sua manutenção, mas trazia o inconveniente de parar totalmente a operação da frota das 17 às 19 horas e das 5 às 7 horas. Nestes períodos, a manutenção da moagem da usina era totalmente feita com a cana armazenada no pátio (estoque de cana). Assim, no período em que a frota estivesse em operação, a entrega efetuada pelos caminhões deveria ser capaz de atender a moagem e ainda estocar no pátio uma quantidade adicional de cana para as horas de frota parada e para suprir a inércia do transporte no início do próximo turno. Esse volume de cana adicional era bastante alto, de cerca de $1000 \mathrm{t}$ de cana acumulada no pátio no final do turno de transporte, o que não era desejado, pois a cana ficava sujeita à deterioração e perda de açúcar.

Com o objetivo de garantir a moagem ao longo do dia, sem risco de falta de cana e com a mesma infraestrutura de equipamentos, três cenários alternativos foram propostos para estudo, nos quais o horário de entrada de trabalho da frota era dividido em duas turmas. Esses cenários foram sempre de dois turnos, mas diferiam quanto à defasagem da entrada da segunda turma:

- Duas turmas escalonadas com 2 horas de diferença;

- Duas turmas escalonadas com 4 horasde diferença; e

- Duas turmas escalonadas com 6 horas de diferença.

Em conjunto com a equipe da usina, definiu-se que sempre a turma 1 seria formada pelas frentes $1,3,4$ e 5 e a turma 2 seria formada pela frente 2 . A frente 2 era de cana inteira e possuía maior infraestrutura de equipamentos, o que poderia atender melhor a continuidade da moagem quando da parada da turma 1 .
Em comparação com o sistema de dois turnos e uma turma, o escalonamento garantia que nas 24 horas do dia, sempre haveria ao menos uma turma em operação, o que minimizaria o risco de falta de cana e possibilitaria reduzir o volume de cana estocada no pátio ao mesmo tempo em que a jornada se mantivesse abaixo de 10 horas.

Dada a complexidade do sistema devido à interação entre recursos e entidades e a variabilidade das operações (caráter estocástico dos eventos), decidiu-se elaborar um modelo de simulação para avaliar as três alternativas de turnos em comparação ao sistema vigente. Nesse sentido, a questão de pesquisa versa sobre a identificação do regime de turnos de trabalho que consegue conciliar o abastecimento contínuo de cana à usina com as jornadas dentro do limite legal e com o pátio de cana inteira mantido num nível idealmente baixo, mas sem ricos de falta de cana. Para fornecer melhor visualização dos cenários sob estudo, as Tabelas 2, 3, 4 e 5 apresentam respectivamente os sistemas de trabalho avaliados.

\subsection{Metodologia}

A metodologia trabalhada neste estudo de caso segue, em linhas gerais, as referências de estudos em simulação indicadas por Freitas Filho (2008), Banks (1998), Law e Kelton (1991) e Pegden e Shannon, Sadowski (1995).

A oportunidade da pesquisa surgiu a partir do interesse de uma usina em resolver um problema de gestão para um sistema real em operação. Após o recorte do problema de pesquisa e a identificação de alternativas possíveis de regime de turnos para seus colaboradores, definiu-se que a forma de abordagem utilizaria simulação computacional, em virtude da possibilidade de entender o comportamento dinâmico de algumas variáveis relativas aos sistemas de CCT, como o volume de cana no pátio e as jornadas de trabalho. Na sequência, um cronograma foi estipulado visando definir o uso de recursos humanos e computacionais e estabelecer um prazo para a execução do projeto. Essas decisões tomadas em conjunto com a equipe da usina correspondem 
à fase de conceituação e infraestrutura do projeto. Alguns dados seriam obtidos via sistema de controle da frota da usina, mas outros ainda seriam coletados em campo.

A fase de modelagem englobou atividades que foram feitas em paralelo, como a coleta e a preparação de dados, além da própria modelagem. Os dados utilizados pelo modelo foram coletados por dois meses de safra e podem ser divididos em três grandes grupos:

- Eventos de operações produtivas: tomados com base em medições da duração de operações produtivas (tempo de colheita, tempo de deslocamento dos tratores rebocando carretas vazias e carregadas e outros) em dias alternados e em situações diversas apresentadas pelas frentes de corte e carregamento (Apêndice 1).
- Eventos de manutenção: com base em estimativas da equipe da usina, especialistas em manutenção (Apêndice 2) e nos registros do sistema de controle de oficina (Apêndice 3).

Os dados brutos foram processados no software Input Analyzer para levantar as distribuições teóricas de probabilidade para representação dos eventos no modelo. Os testes de aderência de Chi-quadrado $\left(\mathrm{Chi}^{2}\right)$ e Kolmogorov-Smirnov (KS) foram aplicados observando-se os valores de $p$-value. Quando houve baixa aderência entre os dados e as distribuições teóricas de probabilidade ( $p$-value $<0,1$ ), utilizaram-se distribuições empíricas para representar os eventos.

- Dados gerais: como distâncias médias entre frentes de corte e usina, cargas transportadas por

Tabela 2. Sistema com uma turma.

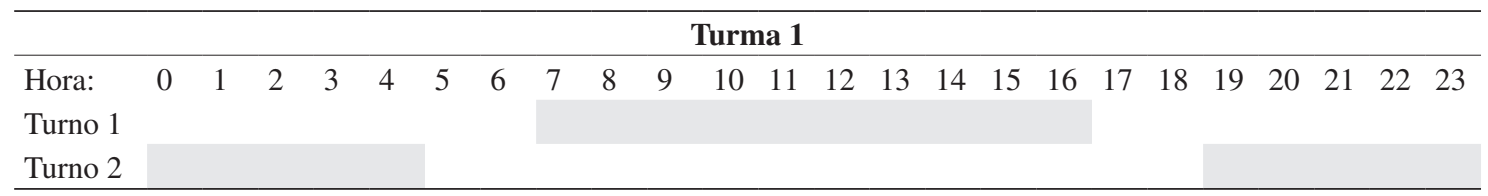

Tabela 3. Sistema com duas turmas escalonadas com 2 horas de diferença.

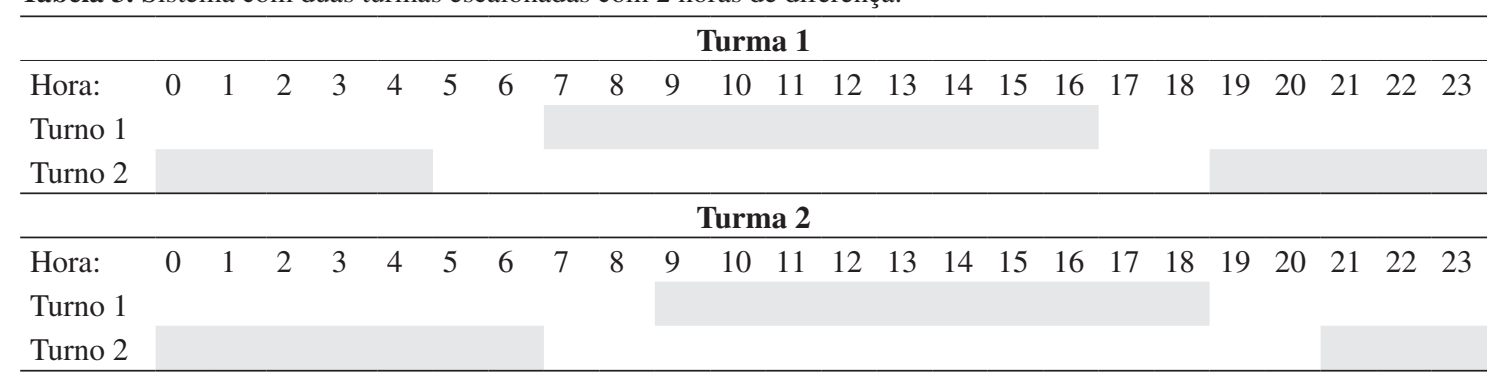

Tabela 4. Sistema com duas turmas escalonadas com 4 horas de diferença.

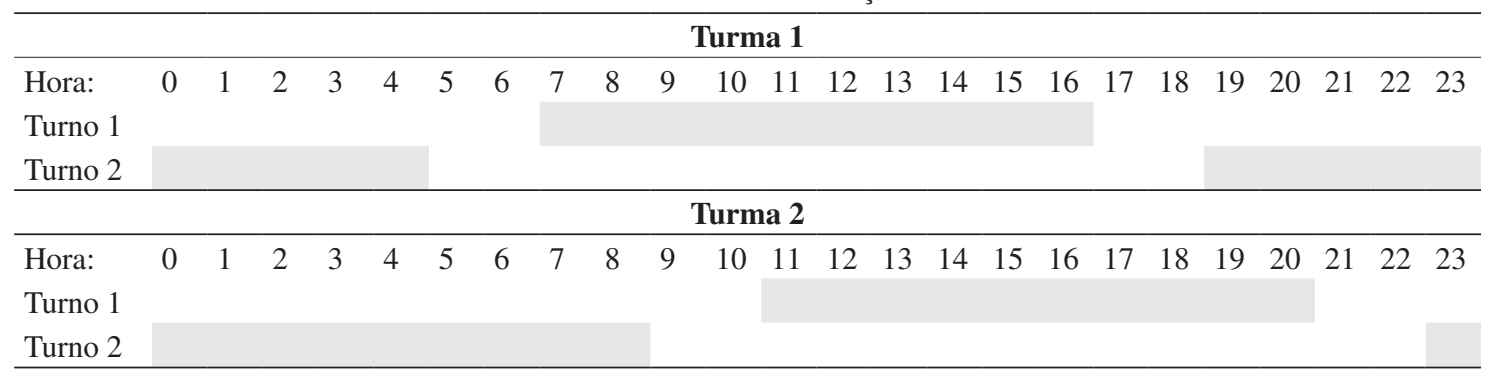

Tabela 5. Sistema com duas turmas escalonadas com 6 horas de diferença.

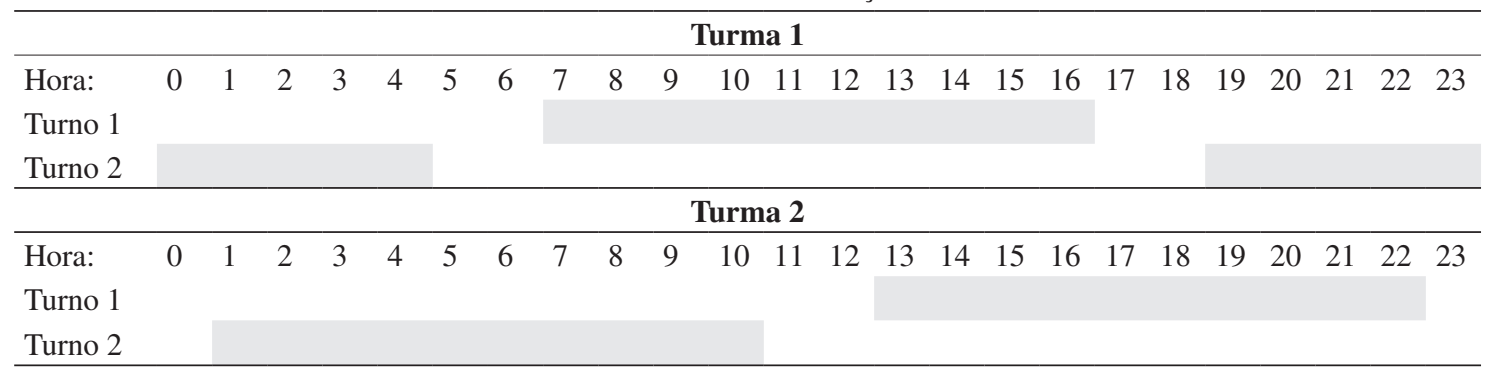


viagem e velocidades dos caminhões vazios e carregados.

Em paralelo à preparação de dados, um modelo de simulação conceitual foi elaborado, com o objetivo de listar as variáveis independentes de interesse (dados de entrada) e os dados significativos a serem obtidos via modelo de simulação (dados de saída). Uma vez que estas informações foram definidas, partiu-se para a tradução do modelo conceitual em uma linguagem computacional, no caso, o software Arena.

De posse do modelo de simulação computacional e dos dados já preparados para inserção no modelo, foi possível passar à última etapa da fase de modelagem, a validação.

O processo de validação visou garantir que os resultados fornecidos pelo modelo de simulação possuíam aderência ao sistema real. Os dados do sistema real (quantidade de equipamentos, distâncias, cargas, etc.) foram inseridos no modelo de simulação, que foi executado e gerou os resultados simulados (produções, quantidade de viagens, e outros). Estes resultados foram comparados aos mesmos parâmetros do sistema real.

O período de referência para a validação do modelo foi a primeira quinzena do mês de setembro da safra 2004/2005. Para esse período, uma série de dados foi obtida dos sistemas de controle da usina: a quantidade de cana transportada por frente por dia, a distância média ponderada e a carga média dos caminhões no período.

O modelo elaborado para o período de validação foi configurado para moagem diária de 11.800 t.dia $^{-1}$ e moagem de pico de 12.200 t.dia $^{-1}$ em 4 frentes de corte e carregamento, sendo três de cana inteira e um de cana picada. A Tabela 6 apresenta os resultados comparativos das produções diárias de cana para os sistemas real e simulado.

A diferença percentual obtida entre os sistemas real e simulado apresentou valores inferiores a $1 \%$ na comparação por frente de corte. Uma vez que o sistema possui muitas variáveis que interagem entre si (cargas médias, distâncias médias, quantidade de equipamentos, velocidades, manutenções e outras), que poderiam comprometer a validação, as diferenças obtidas foram consideradas excelentes. Variações de até $5 \%$ em relação aos valores reais seriam consideradas adequadas.

Para a maioria dos modelos de simulação não é possível efetuar a validação com base na comparação com valores reais, pois os sistemas simulados são inexistentes. Neste caso, embora a validação do modelo tenha sido feita para o mês de setembro de 2004, o estudo foi feito para as condições da safra $2005 / 2006$. Isto foi possível porque as principais condições operacionais de CCT se mantiveram e o modelo validado foi modificado apenas o necessário para contemplar os quatro cenários de interesse.
Por fim, após a validação do modelo, a etapa de simulação consistiu na experimentação do modelo, ou seja, sua execução com posterior análise dos resultados, contemplando os quatro sistemas de turnos de trabalho.

O modelo foi simulado por 180 dias, duração de uma safra, e os resultados foram analisados para um dia médio com moagem máxima (situação de pior caso). O período foi suficiente para a ocorrência das manutenções dos equipamentos, cujo banco de dados foi extraído para uma safra. Três instrumentos de análise foram gerados a cada simulação:

- Planilha resumo do cenário; com dados resultantes de desempenho de equipamentos (capacidades operacionais; percentuais de tempo em operação, em manutenção e ociosos); produções de cana por frente; jornadas de trabalho e outros;

- Gráfico de volume médio de estoque de cana no pátio (gráfico de pátio médio), que permitiu acompanhar a variação do pátio de cana ao longo do dia indicando os instantes de máximo e mínimo estoque. Cada ponto representa a média para aquele instante do dia (0h0min; 0h5min; 0h10min, etc.) dos valores registrados durante os dias simulados (Figura 7); e

- Gráfico de distribuição de frequência da cana no pátio, que forneceu o percentual do tempo simulado em que o pátio estava em cada classe de frequência, correspondente à quantidade de cana armazenada. Cada classe de frequência representa uma faixa de $100 \mathrm{t}$ de cana no pátio (Figura 8).

\subsection{Resultados e discussões}

A Tabela 7 apresenta a comparação das produções dos quatro cenários propostos para avaliação, referentes à safra 2005/2006.

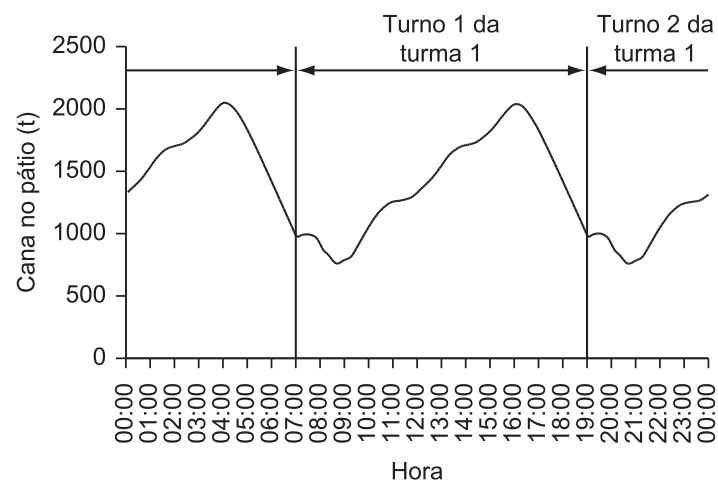

Figura 7. Gráfico de acompanhamento do volume médio de estoque de cana do pátio (pátio médio) - validação. 
Todos os cenários atingiram as produções totais estipuladas para atender a capacidade de moagem da usina. Apenas o cenário 2, que contempla o escalonamento em 2 horas, apresentou entrega de cana picada abaixo da cota em $5 \mathrm{t}(0,12 \%$ de diferença).

As jornadas, que são diretamente vinculadas ao cumprimento da cota estipulada de entrega de cana, são apresentadas na Tabela 8.

As jornadas dos cenários com escalonamento apresentaram uma pequena redução em comparação ao cenário com uma turma. Os maiores ganhos quanto à jornada foram obtidos no cenário com escalonamento de 6 horas, da ordem de 0,2 horas para as turmas de cana inteira, ou seja, 12 min. de redução de jornada em média. Em todos os cenários, as frentes de cana picada apresentaram jornadas maiores que $10 \mathrm{~h}$. Alternativas para a redução dessa jornada seriam o aumento de equipamentos para lidar com a cana picada ou a redução da cota de cana picada, com o consequente aumento da cota de cana inteira. Estas alternativas, porém, não foram consideradas neste trabalho.

Alguns aspectos são importantes quando se analisam as jornadas do sistema. O sistema simulado é baseado em regras que admitem certa flexibilidade no sistema real. Exemplos de regras e procedimentos com maiores restrições no sistema simulado são:

- No sistema real, na percepção de falta de cana por parte da área industrial é possível reduzir a velocidade de moagem. No modelo, a taxa de moagem considerada foi de pico.

- Ao ocorrer quebra simultânea de muitos equipamentos (caminhões, máquinas, etc.), pode-se alterar a cota a ser entregue no dia, enquanto no modelo estes valores são fixos.

- Para garantir a moagem, pode-se gerenciar a distância média como alternativa de compensação e a transferência de equipamentos entre as frentes. No modelo, isto não ocorre.

- No sistema real, para se garantir o cumprimento da cota com jornada menor, pode-se postergar a manutenção de algum equipamento, o que não ocorre com o modelo.

- As velocidades dos caminhões foram definidas por equações ou valores determinísticos,

Tabela 6. Comparativo entre as produções reais e simuladas.

\begin{tabular}{lccccc}
\hline \multirow{2}{*}{ Sistema } & \multicolumn{5}{c}{ Produções diárias de cana $\left(\right.$ t.dia $\left.^{-1}\right)$} \\
\cline { 2 - 6 } & Frente 1 & Frente 2 & Frente 3 & Frente 4 & Total \\
\hline Real & 3.861 & 2.754 & 2.200 & 2.948 & 11.763 \\
Simulado & 3.895 & 2.758 & 2.203 & 3.973 & 11.829 \\
Dif. percentual (\%) & 0,9 & $-0,2$ & 0,2 & 0,9 & 0,6 \\
\hline
\end{tabular}

Tabela 7. Comparação das produções dos cenários simulados.

\begin{tabular}{ccccc}
\hline \multirow{2}{*}{ Cenário } & Descrição & \multicolumn{3}{c}{ Produções } \\
\cline { 3 - 5 } & & Cana Inteira (t) & Cana Picada (t) & Total (t) \\
\hline 1 & 1 turma & 8.008 & 4.011 & 12.019 \\
2 & 2 turmas escalonadas - 2 horas & 8.266 & 3.995 & 12.261 \\
3 & 2 turmas escalonadas - 4 horas & 8.268 & 4.011 & 12.279 \\
4 & 2 turmas escalonadas - 6 horas & 8.182 & 4.009 & 12.191 \\
\hline
\end{tabular}

Tabela 8. Comparação das jornadas obtidas nos cenários.

\begin{tabular}{|c|c|c|c|c|c|c|c|}
\hline \multirow[t]{4}{*}{ Cenário } & \multirow[t]{4}{*}{ Descrição } & \multicolumn{6}{|c|}{ Jornadas } \\
\hline & & \multicolumn{4}{|c|}{ Turma 1 (trocas às 7 e às 19 horas) } & \multirow{2}{*}{\multicolumn{2}{|c|}{$\begin{array}{c}\text { Turma } 2 \text { (escalonada) } \\
\text { Cana Inteira }\end{array}$}} \\
\hline & & \multicolumn{2}{|c|}{ Cana Inteira } & \multicolumn{2}{|c|}{ Cana Picada } & & \\
\hline & & $\begin{array}{l}\text { Turno } 1 \\
\text { (horas) }\end{array}$ & $\begin{array}{c}\text { Turno } 2 \\
\text { (horas) }\end{array}$ & $\begin{array}{l}\text { Turno } 1 \\
\text { (horas) }\end{array}$ & $\begin{array}{l}\text { Turno } 2 \\
\text { (horas) }\end{array}$ & $\begin{array}{l}\text { Turno } 1 \\
\text { (horas) }\end{array}$ & $\begin{array}{l}\text { Turno } 2 \\
\text { (horas) }\end{array}$ \\
\hline 1 & 1 turma & 10,2 & 10,1 & 10,5 & 10,5 & - & - \\
\hline 2 & $\begin{array}{c}2 \text { turmas escalonadas } \\
\text { em } 2 \text { horas }\end{array}$ & 10,2 & 10,1 & 10,6 & 10,6 & 10,1 & 10,1 \\
\hline 3 & $\begin{array}{c}2 \text { turmas escalonadas } \\
\text { em } 4 \text { horas }\end{array}$ & 10,1 & 10,1 & 10,6 & 10,5 & 10,0 & 10,2 \\
\hline 4 & $\begin{array}{c}2 \text { turmas escalonadas } \\
\text { em } 6 \text { horas }\end{array}$ & 10,0 & 10,0 & 10,5 & 10,4 & 9,8 & 9,9 \\
\hline
\end{tabular}




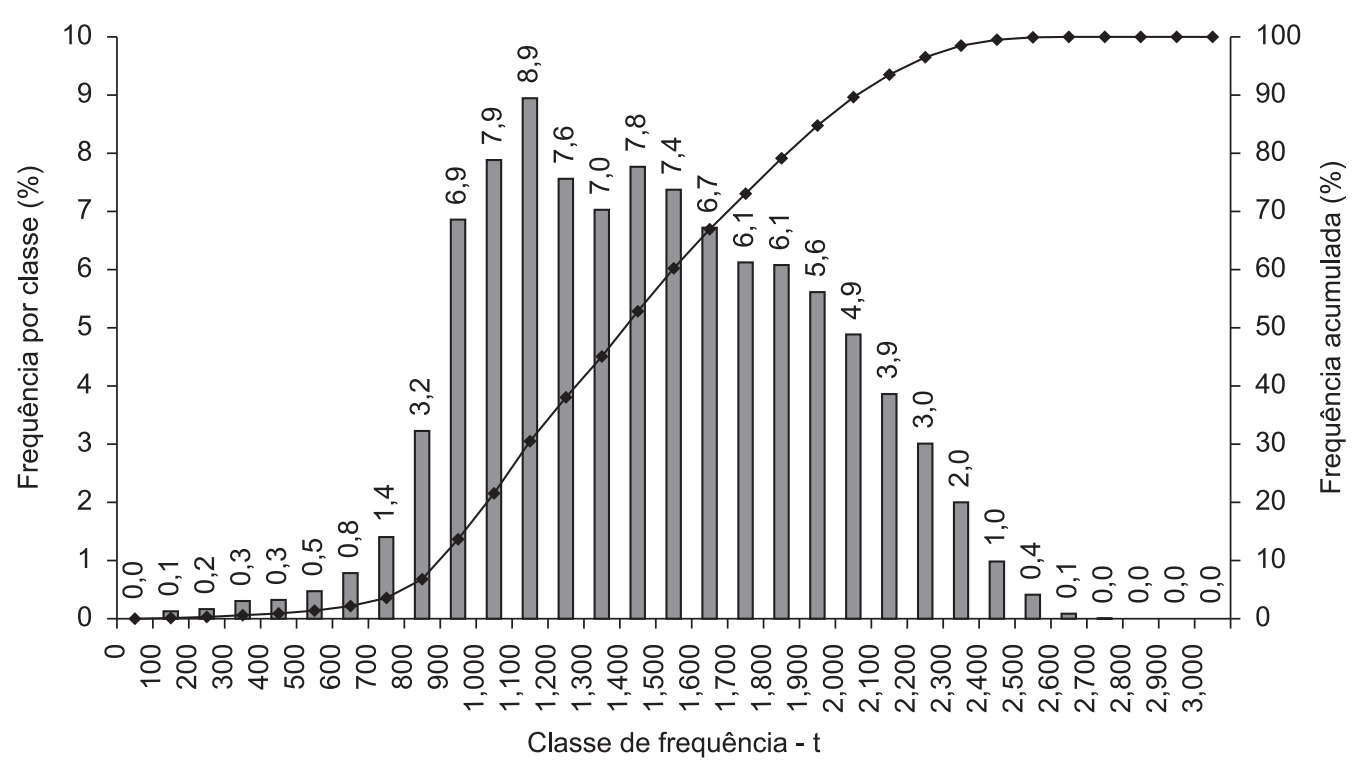

口 Frequência por classe (\%) $\multimap$ Frequência acumulada (\%)

Figura 8. Distribuição de frequência da cana no pátio - validação.

Tabela 9. Comparação dos parâmetros relativos ao pátio.

\begin{tabular}{ccccc}
\hline Cenário & Descrição & \multicolumn{3}{c}{ Pátio } \\
\cline { 3 - 5 } & & $\begin{array}{c}\text { Pátio médio } \\
\text { absoluto }(\mathbf{t})\end{array}$ & $\begin{array}{c}\text { Cana trabalhada } \\
\text { pelas pás (t) }\end{array}$ & $\begin{array}{c}\text { Amplitude } \\
\text { pátio médio (t) }\end{array}$ \\
\hline 1 & 1 turma & 1.284 & 11.921 & 1200 \\
2 & 2 turmas escalonadas em 2 horas & 634 & 9.647 & 800 \\
3 & 2 turmas escalonadas em 4 horas & 543 & 9.048 & 600 \\
4 & 2 turmas escalonadas em 6 horas & 510 & 8.825 & 600 \\
\hline
\end{tabular}

permanecendo constantes na simulação, o que não ocorre no sistema real.

Por não terem sido considerados tais procedimentos no modelo, os resultados fornecidos são de postura conservadora, mas que ainda possibilitam muita flexibilidade.

O maior impacto do escalonamento dos turnos foi observado na cana armazenada no pátio. A Tabela 9 compara os parâmetros relativos ao pátio entre os cenários simulados.

Pode-se observar que o escalonamento progressivo dos turnos de duas em duas horas contribuiu para a redução do volume de cana no pátio. $\mathrm{O}$ volume de cana trabalhado pelas pás carregadoras também evidencia esse fato. A redução do estoque de cana é positiva em termos da qualidade da matéria-prima, mas, à medida que o volume médio de cana estocada reduz, aumenta o risco de falta de cana.

Foi possível acompanhar essa característica pelos gráficos de pátio médio e de distribuição de frequência da cana no pátio de cada um dos cenários. Com o escalonamento, o suprimento de cana foi mais bem distribuído ao longo das 24 horas, pois sempre havia transporte em operação. O pátio médio mostrou-se mais estável em torno da média, embora com valor absoluto menor. A melhor distribuição foi comprovada pela amplitude do pátio médio, que apresentou redução com o aumento do escalonamento. A Figura 9 apresenta o comportamento do pátio médio de cana ao longo do dia, em conjunto para todos os cenários simulados.

Foi possível perceber pelo gráfico de pátio médio que, fora o horário das trocas de turno da turma 1 (7 e 19 horas), os horários críticos do sistema em todos os cenários foram em torno das $8 \mathrm{~h} 30$ e $20 \mathrm{~h} 30$.

Às 7 e às 19 horas, a cana estocada sobre rodas garantiu o abastecimento das moendas até o transporte do turno que estava iniciando entrar em regime. Às 8h30min e às 20h30min, o estoque sobre rodas já havia sido descarregado e o pátio médio atingiu o mínimo estoque, dada a inércia dos caminhões que iniciaram o turno às 7 e 19 horas. Apenas a partir das 


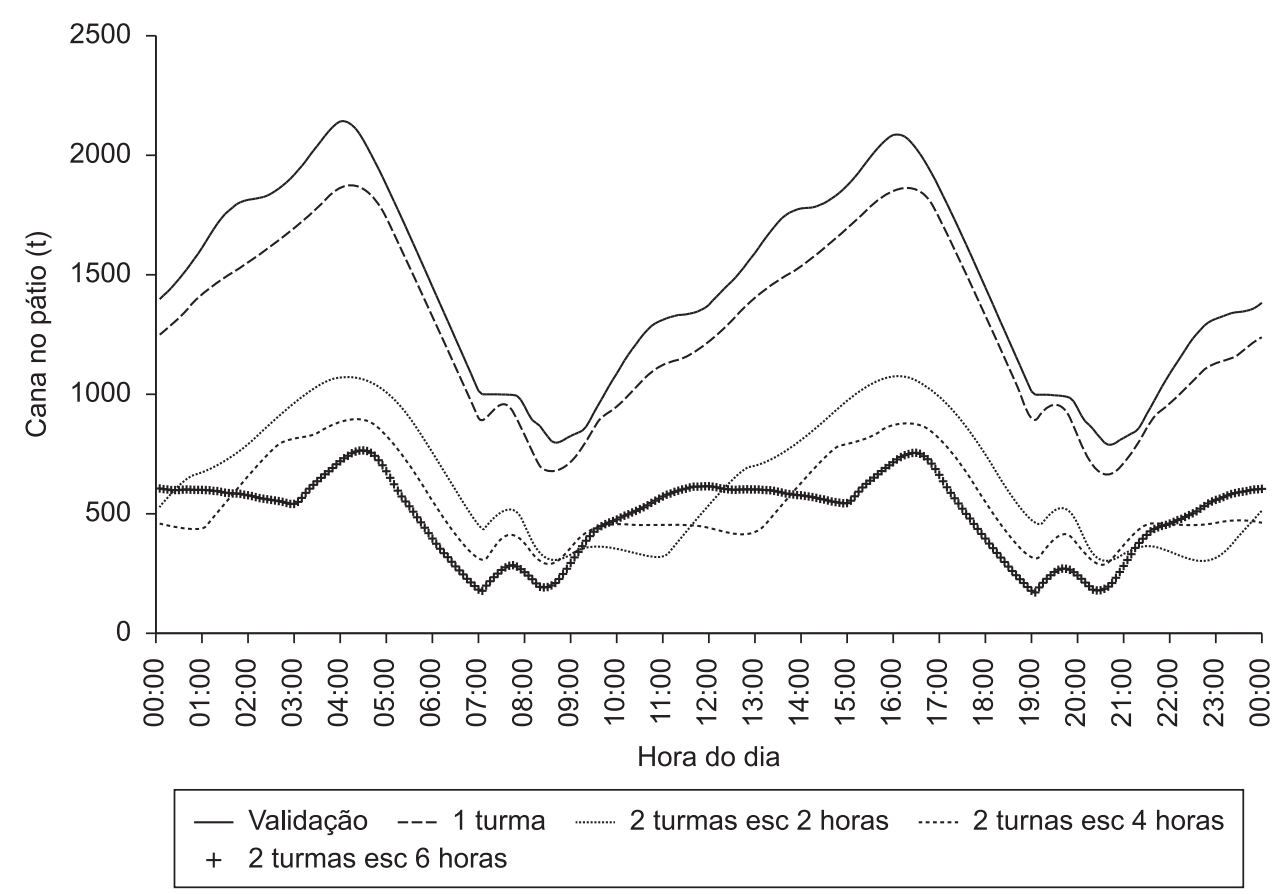

Figura 9. Comparação do acompanhamento do volume médio de estoque de cana do pátio (pátio médio) para todos os cenários simulados.

8h30min e 20h30min iniciou-se o retorno do campo dos caminhões com as primeiras viagens.

Nos turnos escalonados, a cana trabalhada pela turma 1 possuía melhor chance de abastecimento da usina por dividir a cana em dois tipos (inteira e picada) e quatro frentes ( 2 de cana inteira e 2 de cana picada) do que a turma 2 que contempla apenas uma frente de cana inteira (frente 2). Prova disso é o inicio do retorno dos caminhões da primeira viagem da turma 2 cujo retorno, devido à distância da frente 2 , demorou em torno de 30 min adicionais em relação à turma 1.

Havia uma expectativa de que o cenário com escalonamento de seis horas fosse apresentar um melhor resultado, uma vez que esse escalonamento possui períodos iguais de sobreposição de jornadas das turmas 1 e 2 em quatro horas ao longo do dia: das 13 às 17 horas, das 19 às 23 horas, da 1 às 5 horas e das 7 às 11 horas. No entanto, a divisão da cana a ser trazida entre as duas turmas não era balanceada, visto que a turma 2, formada apenas pela frente 2 de cana inteira, possuía capacidade de entrega de aproximadamente 3.500 t.dia ${ }^{-1}$, ou seja, apenas $30 \%$ da capacidade de moagem. Por este motivo, esta alternativa se mostrou inviável pelo risco de falta de cana no pátio $(10,3 \%$ na classe de frequência entre 0 e 100 t).

Dos demais cenários, o escalonamento das duas turmas em quatro horas já apresenta um risco menor de falta de cana $(6,6 \%$ na classe de frequência entre 0 e 100 t) com a duração das jornadas pouco maiores que o cenário com 6 horas de escalonamento (10,1 horas em média para as frentes de cana inteira).
Considerando que ainda há possibilidades de ganho de produtividade no sistema real que não conseguem ser expressos totalmente na simulação, este cenário apresenta maior segurança para implementação, aliando a vantagem de se reduzir o estoque de cana inteira no pátio.

\section{Conclusões}

O estudo atingiu o objetivo de desenvolver um modelo de simulação das operações de corte, carregamento e transporte (CCT) de cana-de-açúcar que pudesse ser utilizado para avaliar a política de turnos de trabalho para sua frota de máquinas e veículos. A simulação permitiu identificar os principais fatores que condicionam as operações do sistema de CCT, sendo o pátio o parâmetro de maior influência, por regular o cálculo das cotas a serem entregues e, consequentemente, as jornadas de trabalho dos operadores e motoristas.

O modelo permitiu explorar detalhes dos cenários de interesse, como a variação do estoque de cana inteira no pátio ao longo do dia, o cálculo das jornadas de trabalho, a mensuração do risco de falta de matériaprima para moagem e os períodos do dia em que esse risco era maior. Estas informações não seriam possíveis de serem obtidas caso fossem utilizadas outras abordagens. Nesse sentido, a simulação possibilitou a aquisição de novos e maiores conhecimentos para 
avaliar a interação entre os recursos e compreensão geral do sistema como um todo (visão sistêmica).

Focando os objetivos do estudo de caso, os cenários simulados visavam a utilização dos equipamentos com jornadas de trabalho abaixo do limite de 10 horas por turno e a garantia da continuidade de abastecimento da usina. O escalonamento dos turnos foi eficiente para atingir o objetivo de redução das jornadas dos equipamentos de cana inteira, porém não se reduziu a jornada dos equipamentos de cana picada. Verificou-se também que, ao mesmo tempo que o escalonamento reduziu a quantidade de cana em estoque, significando cana de melhor qualidade, o risco de falta de cana foi evidenciado. Estas observações, possíveis de serem analisadas por meio do modelo de simulação, justificam a contribuição científica deste estudo de caso, com natureza explanatória, para entender as relações de casualidade das variáveis de interesse: risco de falta de cana e jornadas de trabalho, ambas afetadas pelo regime de turnos.

Para avaliar o impacto devido apenas ao sistema de turnos, foram mantidas as mesmas condições operacionais (distâncias médias, cargas, quantidade de equipamentos, etc.) para todos os cenários simulados. Dos cenários escalonados, a alternativa com escalonamento em 4 horas apresentou melhor desempenho, balanceando-se jornadas, produções por tipo de cana, o estoque com cana mais nova e menor risco de faltar cana para moagem.

Ao ser implementado, o escalonamento com 4 horas de defasagem confirmou as vantagens observadas na simulação quanto à jornada e à estabilidade do estoque de cana, com menor flutuação em comparação aos outros cenários simulados. Essas vantagens foram confirmadas pela gerência da usina durante o período em que o sistema entrou em operação. No entanto, o cenário com apenas uma turma apresenta algumas características, não contempladas no modelo de simulação, que ainda levaram à sua permanência, como a necessidade de transporte adicional para movimentar as equipes para as frentes de corte e carregamento e os próprios horários de troca de turno, que dificultariam a organização de outras atividades paralelas dos operadores.

Embora a modelagem consuma muito tempo, a partir do modelo validado, a rapidez de se gerar resultados mostrou-se interessante, dada a riqueza de detalhes que a simulação proporciona. O tempo de simulação do modelo, considerando 180 dias de safra, foi de aproximadamente uma hora com exportação direta dos dados para planilhas eletrônicas.

Novas alternativas operacionais podem ser testadas para aprimorar o sistema de CCT a partir do modelo elaborado, como o sistema de três turnos de trabalho, quantificação de máquinas, aumento da moagem da usina e implantação de horários de refeição, dentre outros. Tais decisões são típicas da equipe gerencial das usinas e os modelos de suporte à decisão podem auxiliar a análise destas variantes operacionais.

\section{Referências}

BALLOU, R. H. Gerenciamento da cadeia de suprimentos/ logística empresarial. 5. ed. Porto Alegre: Bookman, 2006.

BANKS, J. Handbook of simulation. Atlanta: John Wiley \& Sons, 1998.

BOWERSOX, D. J.; CLOSS, D. J.; COOPER, M. B. Gestão logística de cadeias de suprimentos. Porto Alegre: Bookman, 2006.

BRASIL. Ministério da Agricultura, Pecuária e Abastecimento. Secretaria de Produção e Comercialização. Departamento do Açúcar e do Álcool. Apresenta resumo da produção sucroalcooleira na safra 2007/2008. Disponível em: $<$ http://mapas.agricultura.gov.br/spc/daa/Resumos/ Maio07-08_2.pdf>. Acesso em: 11 fev. 2009.

DÍAZ, J. A.; PÉREZ, I. L. Simulation and optimization of sugar cane transportation in harvest season. In: WINTER SIMULATION CONFERENCE, 32., 2000, Orlando. Proceedings... Orlando, 2000. p. 1114-1117.

FREITAS FILHO, P. J. Introdução à modelagem e simulação de Sistemas - com Aplicações em Arena. 2. ed. Florianópolis: Visual Books, 2008.

HANSEN, A. C.; BARNES, A. J.; LYNE, P. W. L. Simulation modeling of sugarcane harvest-to-mill delivery systems. Transactions of the ASAE, v. 45. n. 3, p. 531-538, 2002.

IANNONI, A. P. Análise do sistema logístico de descarga de cana-de-açúcar: um estudo de caso em uma grande usina na região de Ribeirão Preto. 2000. 159 f. Dissertação (Mestrado em Engenharia de Produção)-Departamento de Engenharia de Produção, Universidade Federal de São Carlos, São Carlos.

KELTON, W. D.; SADOWSKI, R. P.; SADOWSKY, D. A. Simulation with Arena. New York: McGraw-Hill, 1998.

LAW, A. M.; KELTON, W. D. Simulation modeling and analysis. 2. ed. New York: McGraw-Hill, 1991.

LOPES, M. B. Simulação de um sistema de carregamento e transporte de cana-de-açúcar. 1995. 143 f. Dissertação (Mestrado em Engenharia Agronômica)-Escola Superior de Agricultura “Luiz de Queiroz”, Universidade de São Paulo, Piracicaba.

MILAN, M. Improving operational management of harvest, transport and mechanization for sugar cane in Brazil. 1992. 226 f. Thesis (Ph.D. in Agricultural Engineering)-Cranfield Institute of Technology.

PEGDEN, C. D.; SHANNON, R. E.; SADOWSKI, R. P. Introduction to simulation using SIMAN. 2. ed. New York: McGraw-Hill, 1995.

RIPOLI, T. C. C.; RIPOLI, M. L. Biomassa de canade-açúcar: colheita, energia e ambiente. Piracicaba, 2004. p. 222.

YAMADA, M. C.; PORTO, A. J. V.; INAMASU, R. Y. Aplicação dos conceitos de modelagem e de redes de Petri na análise do processo produtivo da indústria sucroalcooleira. Pesquisa Agropecuária, v. 37, n. 6, p. 809-820, 2002.

YIN, R. K. Case study research: design and methods. 2. ed. London: Sage, 1994. 


\section{Apêndice A - Eventos de operações produtivas}

\begin{tabular}{|c|c|}
\hline Operação agrícola & Distribuição \\
\hline Acerto de carga do caminhão de cana inteira & $\operatorname{NORM}(2.49,0.769)$ \\
\hline Carregamento de cana inteira (caminhão ou julieta) & $\operatorname{NORM}(11.8,2.94)$ \\
\hline Carregamento de cana picada (2 transbordos) & 6+LOGN(6.82,4.77) \\
\hline Descarga do caminhão na mesa de cana picada & 5+GAMM(1.57,3.1) \\
\hline Descarga do caminhão no hilo & $\begin{array}{c}\operatorname{CONT}(0.000,5.000,0.165,5.889,0.536,6.778,0.619, \\
7.667,0.649,8.556,0.711,9.444,0.794,10.333,0.876 \\
11.222,0.959,12.111,1,3.000)\end{array}$ \\
\hline Descarga do caminhão no pátio & $\operatorname{NORM}(7.36,1.03)$ \\
\hline Desengate de julietas & $\operatorname{NORM}(1.5,0.5)$ \\
\hline Deslocamento do caminhão carregado no campo & $\operatorname{LOGN}(3.76,1.88)$ \\
\hline Deslocamento do caminhão vazio & $\operatorname{LOGN}(2.65,2.04)$ \\
\hline Deslocamento do caminhão-transbordo carregado & $\operatorname{NORM}(4.33,1.77)$ \\
\hline Deslocamento do caminhão-transbordo vazio & $\operatorname{LOGN}(8.63,6.44)$ \\
\hline Deslocamento do trator carregado & $\operatorname{LOGN}(3.76,1.88)$ \\
\hline Deslocamento do trator-reboque vazio & $\operatorname{LOGN}(2.65,2.04)$ \\
\hline Deslocamento sozinho do trator-reboque & $\operatorname{GAMM}(1.09,2.92)$ \\
\hline Engate de julietas & $\operatorname{NORM}(0.5,0.01)$ \\
\hline Limpeza de carroceria & $\operatorname{NORM}(2.49,0.769)$ \\
\hline Limpeza pesada & $\operatorname{NORM}(7.22,2.59)$ \\
\hline Pesagem do "treminhão" & NORM $(1.07,0.137)$ \\
\hline Sondagem & $\begin{array}{c}\operatorname{CONT}(0.000,1.999,0.130,2.461,0.190,2.923,0.210 \\
3.385,0.230,3.847,0.380,4.309,0.670,4.772,0.920 \\
5.234,0.990,5.696,1,6.620)\end{array}$ \\
\hline Transbordamento de cana picada para o caminhão & $\begin{array}{c}\operatorname{CONT}(0.000,1.000,0.050,1.339,0.260,1.678,0.470 \\
2.017,0.600,2.356,0.760,2.695,0.890,3.034,0.950 \\
3.373,0.970,3.712,0.990,4.051,1,4.390)\end{array}$ \\
\hline
\end{tabular}




\section{Apêndice B - Eventos de manutenção - Distribuições estimadas pela equipe da usina}

\begin{tabular}{|c|c|}
\hline Manutenção & Distribuição \\
\hline Duração do abastecimento da carregadora & TRIA(10,20,30) \\
\hline Intervalo entre abastecimentos da carregadora & TRIA $(600,720,840)$ \\
\hline Duração da lubrificação da carregadora & $\operatorname{TRIA}(20,30,40)$ \\
\hline Intervalo entre lubrificações da carregadora & TRIA(2640,2880,3120) \\
\hline Duração do abastecimento da colhedora & $\operatorname{TRIA}(10,20,30)$ \\
\hline Intervalo entre abastecimentos da colhedora & $\operatorname{TRIA}(540,600,660)$ \\
\hline Duração da lubrificação da colhedora & TRIA(240,300,360) \\
\hline Intervalo entre lubrificações da colhedora & TRIA(3240,3600,3960) \\
\hline Duração da troca de facas da colhedora & $\operatorname{TRIA}(10,15,20)$ \\
\hline Intervalo entre trocas de facas da colhedora & $\operatorname{TRIA}(600,720,840)$ \\
\hline Duração do abastecimento do trator-reboque & TRIA $(10,20,30)$ \\
\hline Intervalo entre abastecimentos do trator-reboque & TRIA(1320,1440,1560) \\
\hline Duração da lubrificação do trator-reboque & $\operatorname{TRIA}(20,30,40)$ \\
\hline Intervalo entre lubrificações do trator-reboque & TRIA(2640,2880,3120) \\
\hline Duração do abastecimento do caminhão-transbordo & $\operatorname{TRIA}(20,30,40)$ \\
\hline Intervalo entre abastecimentos do caminhão-transbordo & TRIA(1320,1440,1560) \\
\hline Duração da lubrificação do caminhão-transbordo & TRIA(540,600,660) \\
\hline Intervalo entre lubrificações do caminhão-transbordo & $\operatorname{TRIA}(8640,10080,11520)$ \\
\hline Duração do abastecimento do caminhão & $\operatorname{TRIA}(20,30,40)$ \\
\hline Intervalo entre abastecimentos do caminhão & TRIA(1200,1440,1680) \\
\hline Duração da lavagem do caminhão & TRIA(180,240,300) \\
\hline Intervalo entre lavagens do caminhão & TRIA $(8640,10080,11520)$ \\
\hline Bater pneu dos caminhões & $\operatorname{TRIA}(2,3,4)$ \\
\hline
\end{tabular}




\section{Apêndice C - Eventos de manutenção - Distribuições obtidas por ajuste}

$\begin{array}{cc}\text { Manutenção } & \text { Distribuição }\end{array}$

Duração da manutenção no campo $\operatorname{CONT}(0.000,2.999,0.468,28.799,0.780,54.599,0.890,80.399,0.928$,

do trator-reboque

$106.200,0.957,132.000,0.972,157.800,0.981,183.600,0.986,209.400$,

$0.990,235.200,0.994,261.000,0.995,286.800,0.997,312.601,0.997$,

$338.401,0.998,364.201,1,390.001)$

Intervalo entre manutenções no

campo do trator-reboque

CONT(0.000, 4.999, 0.506, 1718.466, 0.695, 3431.933, 0.795, 5145.399,

$0.864,6858.866,0.915,8572.333,0.944,10285.800,0.962,11999.267,0.972$,

$13712.733,0.980,15426.200,0.987,17139.667,0.990,18853.134,0.993$,

20566.601, 0.997, 22280.067, 0.999, 23993.534, 1, 25707.001)

Duração da manutenção na oficina do caminhão de cana inteira

(CONT(0.000, 4.999, 0.926, 997.999, 0.963, 1990.999, 0.977, 2984.000, $0.983,3977.000,0.987,4970.000,0.990,5963.000,0.995,6956.000,0.996$, $7949.001,0.998,8942.001,1,9935.001)) * 0.8$

Intervalo entre manutenções na oficina do caminhão de cana inteira

CONT(0.000, 29.999, 0.392, 3658.999, 0.659, 7287.999, 0.923, 10917.000, 0.980, 14546.000, 0.989, 18175.000, 0.994, 21804.000, 0.998, 25433.000, $0.998,29062.001,0.999,32691.001,1,36320.001)$

Duração da manutenção na oficina do caminhão de cana picada

CONT $(0.000,4.999,0.557,338.666,0.886,672.333,0.936,1005.999$, $0.952,1339.666,0.969,1673.333,0.973,2007.000,0.981,2340.667,0.985$, 2674.333, 0.988, 3008.000, 0.992, 3341.667, 0.995, 3675.334, 0.997, 4009.001, 0.998, 4342.667, 0.998, 4676.334, 1, 5010.001)

Intervalo entre manutenções na oficina do caminhão de cana $\operatorname{CONT}(0.000,49.999,0.269,2140.332,0.444,4230.666,0.578,6320.999$ picada $0.703,8411.333,0.928,10501.666,0.965,12592.000,0.980,14682.333$, 0.988, 16772.667, 0.993, 18863.000, 0.996, 20953.334, 0.997, 23043.667, $0.997,25134.001,0.998,27224.334,0.998,29314.668,1,31405.001)$

Duração da manutenção no campo da carregadora

CONT(0.000, 4.999, 0.760, 63.499, 0.925, 121.999, 0.973, 180.500, 0.985, 239.000, 0.993, 297.500, 0.996, 356.000, 0.998, 414.500, 0.999, 473.001, 1, 590.001)

Intervalo entre manutenções no campo da carregadora

CONT(0.000, 4.999, 0.529, 659.666, 0.760, 1314.333, 0.872, 1968.999, $0.924,2623.666,0.958,3278.333,0.975,3933.000,0.984,4587.667,0.990$, 5242.333, 0.995, 5897.000, 0.997, 6551.667, 0.998, 7206.334, 0.999, $7861.001,1,9825.001)$

Duração da manutenção no campo da colhedora

CONT(0.000, 4.999, 0.638, 81.110, 0.848, 157.222, 0.920, 233.333, 0.959, $309.444,0.979,385.556,0.988,461.667,0.992,537.778,0.996,613.890,1$, 690.001)

Intervalo entre manutenções no campo da colhedora

$8+\operatorname{GAMM}(786,0.926)$

Duração da manutenção no campo do caminhão de cana inteira

CONT(0.000, 4.999, 0.528, 23.999, 0.842, 42.999, 0.915, 61.999, 0.938, $81.000,0.950,100.000,0.965,119.000,0.975,138.000,0.982,157.000$, $0.985,176.000,0.988,195.000,0.991,214.000,0.993,233.001,0.995$, 252.001, 0.998, 271.001, 1, 290.001)

Intervalo entre manutenções no campo do caminhão de cana inteira

CONT(0.000, 4.999, 0.348, 5409.249, 0.539, 10813.499, 0.673, 16217.749, 0.757, 21621.999, 0.816, 27026.250, 0.861, 32430.500, 0.894, 37834.750, $0.913,43239.000,0.933,48643.250,0.947,54047.500,0.956,59451.750$, $0.965,64856.000,0.974,70260.250,0.979,75664.500,0.983,81068.750$, $0.988,86473.001,0.992,91877.251,0.996,97281.501,0.998,102685.751,1$, $108090.001)$

Duração da manutenção no campo do caminhão de cana picada

CONT(0.000, 4.999, 0.556, 27.499, 0.834, 49.999, 0.914, 72.500, 0.952, 95.000, 0.974, 117.500, 0.981, 140.000, 0.986, 162.500, 0.988, 185.001, $0.995,207.501,1,230.001)$

Intervalo entre manutenções no campo do caminhão de cana picada

CONT(0.000, 19.999, 0.462, 8166.499, 0.687, 16312.999, 0.813, 24459.500, 0.879, 32606.000, 0.929, 40752.500, 0.944, 48899.000, 0.970, 57045.500, $0.975,65192.001,0.985,73338.501,1,81485.001)$

Duração da manutenção no campo do caminhão-transbordo

CONT(0.000, 4.999, 0.314, 25.999, 0.614, 46.999, 0.766, 67.999, 0.839, $89.000,0.888,110.000,0.921,131.000,0.936,152.000,0.950,173.000$, 0.960, 194.000, 0.971, 215.000, 0.977, 236.000, 0.991, 257.001, 0.993, $278.001,0.995,299.001,1,320.001)$ 


\section{Apêndice C - Continuação...}

\section{Manutenção}

Intervalo entre manutenções no campo do caminhão-transbordo

Duração da manutenção na oficin do trator-reboque

Intervalo entre manutenções na oficina do trator reboque

Duração da manutenção na oficina da carregadora

Intervalo entre manutenções na oficina da carregadora

Duração da manutenção na oficina do caminhão-transbordo

Intervalo entre manutenções na oficina do caminhão-transbordo

Duração da manutenção na oficina da colhedora Intervalo entre manutenções na oficina da colhedora

\section{Distribuição}

CONT(0.000, 9.999, 0.880, 7087.999, 0.959, 14165.999, 0.974, 21244.000, 0.981, 28322.000, 0.988, 35400.000, 0.989, 42478.000, 0.993, 49556.000, $0.995,56634.001,0.997,63712.001,1,70790.001)$

CONT(0.000, 34.999, 0.536, 1628.749, 0.710, 3222.499, 0.797, 4816.250, $0.855,6410.000,0.913,8003.750,0.928,9597.501,0.942,11191.251,1$, 12785.001)

CONT(0.000, 884.999, 0.441, 20031.666, 0.591, 39178.333, 0.731, 58325.000, 0.817, 77471.667, 0.860, 96618.333, 0.892, 115765.000, 0.925, 134911.667, 0.968, 154058.334, 1, 173205.001)

CONT(0.000, 59.999, 0.597, 2497.374, 0.798, 4934.749, 0.849, 7372.125, $0.882,9809.500,0.908,12246.875,0.916,14684.251,0.975,17121.626,1$, 19559.001)

$370+\operatorname{EXPO}(2.83 e+004)$

CONT(0.000, 59.999, 0.747, 1019.999, 0.914, 1979.999, 0.946, 2940.000, $0.959,3900.000,0.968,4860.000,0.968,5820.000,0.982,6780.000,0.982$, 7740.001, 0.986, 8700.001, 1, 9660.001)

CONT(0.000, 1199.999, 0.153, 8983.333, 0.521, 16766.666, 0.660, 24550.000, 0.726, 32333.333, 0.860, 40116.667, 0.958, 47900.000, 0.972, $55683.334,0.981,63466.667,1,71250.001)$

$270+\operatorname{EXPO}(1.33 e+004)$

$270+\operatorname{EXPO}(4.11 e+004)$ 